\title{
Maintaining Weight Loss by Decreasing Sedentary Time: A Patient and Physician's Perspective
}

\author{
Christopher Montoya · Ethan Lazarus
}

Received: March 7, 2017 / Published online: March 17, 2017

(C) The Author(s) 2017. This article is published with open access at Springerlink.com

\section{ABSTRACT}

This article, co-authored by a patient living with obesity and his obesity medicine specialist, reviews how the patient has successfully lost $200 \mathrm{lb}$ and maintained that loss for over a decade. This was achieved primarily with a behavioral intervention including support visits, a structured food plan, and changes in his physical activity. He did not undergo bariatric surgery. For the majority of this time, he was not treated with anti-obesity medication. This article will review how the patient lost the weight and kept it off, particularly in relationship to the importance of decreasing sedentary time.

Keywords: Maintenance; $\quad$ Metabolism; Movement; Obesity; Physical activity; Sedentary activity; Weight loss; Weight maintenance

Enhanced content To view enhanced content for this article go to http://www.medengine.com/Redeem/ D6F7F060702013E1.

C. Montoya

Castle Rock, CO, USA

E. Lazarus $(\bowtie)$

Clinical Nutrition Center, Greenwood Village, CO, USA

e-mail: DrLazarus@clinicalnutritioncenter.com

\section{PATIENT'S PERSPECTIVE}

My journey to healthy began as a child. I was a big kid, much taller and stockier than the rest of the kids in my classes. I have struggled with maintaining a healthy weight my entire life. Weight issues were not unique to me. Everyone in my family struggled with being overweight at some point. Healthy eating was never prioritized in my household, and overeating was commonplace. As a child and young adult, my weight was controlled by countering the bad eating habits with physical activities such as playing baseball and other sports. On the menu there were plenty of starchy foods, soda, and desserts.

This is just how things were. For me, this was "normal."

Throughout my teenage years, although I was a big guy, I remained very active and relatively healthy. My atrocious eating habits seemingly flew under the radar. Throughout college my activity levels dropped, and I could see my body becoming more sensitive to weight. Let's just say the "Freshmen 30" was really the "Freshmen 50." Being young it was not a big deal. I could surely get the weight off easily just as I had been able to in high school. To put it in perspective, I was $6^{\prime} 2^{\prime \prime}$ with a relatively large frame and so being a bit on the husky side was not a huge issue for me. I was told I "Distributed the weight nicely." Two hundred and fifty pounds? No problem! 
By the age of 23 I was married and having a child. I worked full time and continued school part time; I had done a relatively good job of maintaining a stable weight through the first few years of college, but with this new life as a married, working, studying dad, I became very sedentary. After work I would settle into study and make attempts to spend time with my family, but being active was not a priority.

From the age of 23, starting at about $230 \mathrm{lb}$ and in relatively good shape, to the age of 36 , I gained over $230 \mathrm{lb}$ reaching a terrifying plateau of $460 \mathrm{lb}$. I doubled my weight in 12 years! I was in trouble. Two constants had remained throughout this period of my life: first, the atrocious eating habits, and second, the sedentary lifestyle. To be retrospective for a moment, in addition to not making the healthiest of food decisions, the largest contributors to my bad eating habits were controlling my portions and pace. Seconds were a given. Thirds often if there was more to be had. I did not allow my body to understand what it meant to be satiated. It had to be stuffed. Pant-unbuttoning, not-feeling-too-well stuffed!

I needed a change in my life and quickly! The days of self-pity, wondering what went wrong and dreaming the pounds off needed to be over. I did not feel like a 35-year-old man should. My knees hurt constantly. I could not climb a flight of stairs without stopping for breath. The food, however, oh the food was delicious. I found comfort in daily large lunches with coworkers often consisting of fatty Mexican food with bowl upon bowl of chips and salsa or Chinese or pizza buffets. Heck, if I wanted to lose the weight I would do it. Someday.

I remember the day that turned it around for me. I was going to my first concert at Red Rocks Amphitheater near my home in Denver, Colorado, and what I did not realize about Red Rocks is getting to the entrance at the base of the amphitheater requires a relatively long steep walk from the parking lots at 6000 feet elevation. This is one of the worst experiences of my life. What these days takes me 5 min took me $30 \mathrm{~min}$. Thirty minutes of sheer agony. Foot pain, leg pain from lymphedema, labored breathing, chest pain, drenching sweat, and embarrassment. I made that trek and saw the concert, but on that cold evening my life was changed forever.

I considered bariatric surgery and had basically decided to proceed with the surgery, going so far as to clear the consultations. My primary care physician at the time wanted me to lose some weight before the surgery to improve my odds of long-term success and decrease the risks of surgery. I was in a hurry to get the weight off, but out of respect for the seriousness of the procedure, and the fact that my insurance required that I be on a non-surgical weight loss program for several months before the surgery, I reluctantly agreed to pursue this route He recommended Dr. Lazarus at Clinical Nutrition Center as a resource that would offer the best success.

I initially went to Dr. Lazarus as a means of losing 20 or so pounds to make the bariatric surgery safer for me. At the time, I could not imagine a future without gastric bypass surgery. Even knowing the risks of surgery and potential consequences including malnutrition issues, I was so heavy that I welcomed surgical treatment and wanted it done as soon as possible. I went to my first appointment with Dr. Lazarus with my mind set on the sole short-term goal of reaching a safer weight for surgery.

That was the day that changed the course of the rest of my life. My first appointment weigh-in was $453 \mathrm{lb}$. Dr. Lazarus and I had a frank discussion about what needed to be done, and he suggested that I try his program without my eye on surgery, but rather with an eye on a new way of living, learning not only to incorporate healthy eating and healthy physical activity, but also to control the urge to overeat and understand when my body has had enough food.

I spent the next several months on a protein-sparing modified-fast that was closely monitored by Dr. Lazarus and a team of Registered Dietitians. I was eating few carbohydrates and a lot of lean protein to maintain my muscle mass. Over the course of approximately 16 months, I lost $200 \mathrm{lb}$, dropping to $250 \mathrm{lb}$. This was accomplished without surgery and with very little to no weight loss medication. The change in eating habits was certainly hard at first but my motivation to be healthy 
sustained me. My knees were not hurting, my legs were not swelling, my blood pressure was normal, and, oddly most important to me at the time, I was both able to sit in an airplane seat without feeling ashamed and climb a flight of stairs without stopping halfway to gasp for air. I was given a new lease on life.

But a constant fear arose in me: "How in the world am I going to keep this weight off?"

Accountability was the first weapon to keep the weight off. Going to see the Registered Dietitian on a regular basis would help me stay accountable to myself and remind me that I have help in this battle.

The second was using this newly discovered bank of energy and mobility and putting it to good use. At $300 \mathrm{lb}$, I purchased my first bicycle since childhood and began to ride it frequently, eventually attaining the ability to ride 40 miles. I began to go hiking and even mountain climbing with coworkers. I felt great! This reward was worth the effort. Yes, I was certainly physiologically healthier, but most important to me was that I felt like a person again. I had friends and could climb hills and ride a mountain bike and travel for work in a normal airplane seat!

I have managed to keep off most of that weight and I maintain my relationship with Dr. Lazarus and his wonderful staff of Registered Dietitians to maintain that accountability and remain focused on fighting what I consider to be a disease. I enjoy swimming and biking, and, even though I no longer mountain climb (I have come to the harsh reality that I do not enjoy it as much as I thought I would), I do enjoy walking with my wife and maintaining activity levels that had not previously been possible. Maintaining healthy activity levels along with maintaining a healthy and sustainable diet have helped to make my life a far different reality than I thought was possible the day I walked into Dr. Lazarus' office.

\section{PHYSICIAN'S PERSPECTIVE}

Although I have spent the last 14 years treating obesity, it is rare indeed that I work with an individual like Chris who is able to both lose and sustain a 200-lb drop in weight for over 10 years. For him, this represents a drop of $44 \%$ of his initial body weight, significantly exceeding the expected sustained weight loss from gastric bypass surgery. Chris's account of his change in lifestyle helps explain this dramatic result.

Because obesity is a progressive disease, the body weight tends to rise over the years. Most affected individuals will undergo various self-directed weight loss attempts. These usually consist of a change in diet and an increase in physical activity, or the proverbial "eat less, exercise more."

Unfortunately, within 1 year individuals on average regain $50 \%$ of what was lost [1]. In fact, current science suggests that "eat less, move more" does not in fact lead to sustained weight loss $[2,3]$ because the body will sense the lower weight as abnormally low and respond by increasing appetite signals [4] and decreasing the resting metabolic rate [5]. These adaptations oppose sustained weight loss.

It has long been suggested that if a person loses weight and keeps it off, the risk of regain is mitigated and that the body will establish a new "set point." However, recent evidence suggests that this is incorrect because all the reasons the person developed obesity in the first place persist, in spite of maintaining a stable lower weight, and in fact, the weight-reduced individual must be highly vigilant to prevent weight regain.

A recent study highlighted this, showing that 6 years after a dramatic weight loss, participants on the TV show "The Biggest Loser" had persisting changes in both levels of hunger hormones and in energy expenditure [6]. Even though participants regained on average three-quarters of the lost weight, they still sustained an $11 \%$ weight loss. Maintaining this amount of loss required a significant increase in physical activity because of the opposing effects exerted by the body. In fact, after 6 years, despite weight regain, the resting metabolic rate was still suppressed by $500 \mathrm{kcal}$ compared to expected.

In another study, maintenance of $\geq 10 \%$ reduction in body weight was met by a $20 \%$ decrease in 24-h energy expenditure, a 30\% 
decrease in non-resting energy expenditure, and an improvement in skeletal muscle work efficiency by $20 \%$ [7].

An additional hurdle in maintaining weight loss is that when body weight is reduced, hormonal adaptations resist the reductions in weight [4]. The stomach produces more ghrelin, a hormone that is a potent stimulator of hunger. The small intestine produces less glucagon-like peptide 1, peptide YY and cholecystokinin resulting in a decrease in satisfaction from food, and the reduced body fat mass results in a lower level of leptin resulting in higher levels of hunger. These changes persist for at least 1 year after weight loss. Further studies are needed to see if these changes are permanent.

What does this mean to the person who has lost weight? Whether a person has obesity or not, they will experience a higher level of hunger, a decrease in the ability to feel satisfied when eating, a decrease in energy requirements, and a decrease in the number of calories burned during the day. This is a perfect storm for energy regain. The body will restore the lost weight back to the weight it perceives as "normal." Clinically, patients report a loss in "motivation" or "willpower" with regards to sticking with their eating and exercise plan. In reality, due to these hormonal changes, weight-reduced individuals do not experience satisfaction when they eat the same foods that used to provide satisfaction.

Unfortunately, this concept seems counter-intuitive to both patients affected by obesity and the providers who care for them. After all, if an individual is at an "abnormally high" body mass index (BMI) and they lose weight to a more "normal" BMI, at that point, shouldn't the body protect this new, healthier weight? As it turns out, weight management is more complicated than the old ideas of "energy in, energy out." Understanding that body weight regulation is complex and accepting that, for most individuals affected by obesity, the causes of weight gain are not mitigated by weight loss, we can start to grasp why sustained reductions in weight are so difficult.

Because of these hormonal and metabolic adaptations, we need to explore strategies for sustained weight loss beyond "eat less, move more." In the face of a heightened appetite, decreased metabolism, and improved muscle efficiency, eating less will result in even more hunger and exercising more won't burn the number of calories desired. In addition, trying to eat less and exercise more becomes demotivating. How much is "less"? How much is "more"? And, trying not to eat when hungry leaves people feeling drained of willpower, motivation, and energy.

This is where the idea of decreasing sedentary time becomes interesting. Most people think of their time as either sedentary or exercise. The truth of the matter is that there are a lot of potential steps between sitting and exercising (no pun intended). Instead of focusing on exercising more, we can focus on sitting less.

Excess sitting has been found to increase mortality-in one study, each $1 \mathrm{~h}$ of sitting daily increases overall mortality by $2 \%$ [8]. Many individuals affected by obesity have largely sedentary jobs. Current recommendations suggest that sustaining weight loss may require 1-2 $\mathrm{h}$ per day of moderate physical activity [9]. There can be many hurdles to achieving this ranging from not enough time in the day due to other obligations including work and family to physical limitations (joint osteoarthritis, low back pain, neuropathy, fatigue, etc.). This is why it is important to explore strategies to increase activity that won't aggravate other medical problems or require extra time out of the day.

If instead of exercise we can find time during the work day to not sit, we can make a significant intervention, not only enhancing the individual's odds at successfully maintaining weight loss, but also perhaps decreasing the risks associated with excess sitting.

This concept has been termed non-exercise activity thermogenesis or "NEAT" by Dr. James Levine [10]. NEAT can vary between individuals up to $2000 \mathrm{kcal}$ per day. According to Dr. Levine, individuals with obesity sit for $2.5 \mathrm{~h}$ per day more than sedentary lean counterparts. To reverse obesity, an approach he recommends is to develop individual strategies to promote standing and ambulating time by $2.5 \mathrm{~h}$ per day.

It is now possible to equip an office to allow standing or moving while working. There are standing desks, anti-fatigue mats, workplace treadmills, and even workplace bikes (stand-alone 
or under-desk). There are contraptions that can hold a computer monitor, keyboard, and mouse and enable a sit/stand solution in any home office or workspace at reasonable cost. Individuals can even create their own.

In addition, there has been an explosion of fitness trackers that can be useful to decrease sedentary time. Further, most modern smart phones now have integrated technology to track movement.

Instead of the individual completing a long workday and finding there was no time (or energy) for a workout at the gym, the individual can complete that same workday and achieve many hours of active time, potentially also mitigating the risks of excess sitting.

To date, we do not have an adequate prospective trial proving that these interventions are effective. However, as a clinician with over 14 years of experience in helping patients not only lose weight but also keep it off, it is my observation that decreasing sedentary time not only enhances the odds of success but also improves motivation and decreases appetite. Sitting at a desk results in mindless eating, especially if the food is nearby [11]. Conversely, most individuals aren't accustomed to eating while standing or while walking. In fact, many report that this activity suppresses appetite, perhaps by enhancing norepinephrine activity in the POMC area (pro-opiomelanocortin receptor or appetite regulation center of the hypothalamus). Further, it is my opinion that standing or moving improves energy levels compared with sitting.

I would propose that this would be an exciting area to research. But for now, given the known health risks of excess sitting, a common-sense recommendation to individuals who have lost weight, in lieu of recommending "exercise more" should be to "sit less." After all, isn't this one of the reasons to lose weight in the first place?

\section{ACKNOWLEDGEMENTS}

The authors are fully responsible for all content and editorial decisions and received no financial support or other form of compensation related to the development of this manuscript. All named authors meet the International Committee of Medical Journal Editors (ICMJE) criteria for authorship of this manuscript, take responsibility for the integrity of the work as a whole, and have given final approval for the version to be published.

Disclosures. Ethan Lazarus serves as a consultant and speaker for Novo Nordisk, Orexigen Pharmaceuticals, and Eisai Inc. on the topic of pharmacotherapy for the treatment of obesity. Christopher Montoya has nothing to disclose with regards to the publication of this article.

Compliance with Ethics Guidelines. This article does not contain any new studies with human or animal subjects performed by any of the authors.

Peer Review. Please note, contrary to the journal's standard double-blind peer review process, as a commentary this article underwent review by a member of the journal's Editorial Board.

Open Access. This article is distributed under the terms of the Creative Commons Attribution-NonCommercial 4.0 International License (http://creativecommons.org/licenses/ by-nc/4.0/), which permits any noncommercial use, distribution, and reproduction in any medium, provided you give appropriate credit to the original author(s) and the source, provide a link to the Creative Commons license, and indicate if changes were made.

\section{REFERENCES}

1. Curioni CC, Lourenço PM. Long-term weight loss after diet and exercise: a systematic review. Int J Obes. 2005;29:1168-74.

2. National Heart, Lung, and Blood Institute. Causes of overweight and obesity. 2012. http://www.nh lbi.nih.gov/health/health-topics/topics/obe/causes. Accessed 5 Dec 2016.

3. Schwartz MW, Woods SC, Seeley RJ, Barsh GS, Baskin DG, Leibel RL. Is the energy homeostasis 
system inherently biased toward weight gain? Diabetes. 2003;52:232-8.

4. Sumithran P, Prendergast LA, Delbridge E, et al. Long-term persistence of hormonal adaptations to weight loss. N Engl J Med. 2011;365:1597-604.

5. Bray GA, Smith SR, DeJonge L, et al. Effect of diet composition on energy expenditure during weight loss: the POUNDS LOST Study. Int J Obes (Lond). 2012;36(3):448-55.

6. Fothergill E, Guo J, Howard L, et al. Persistent metabolic adaptation 6 years after "The Biggest Loser" competition. Obesity. 2016;24:1612-9.

7. Rosenbaum M, Vandenborne K, Goldsmith R, et al. Effects of experimental weight perturbation on skeletal muscle work efficiency in human subjects.
Am J Physiol Regul Integr Comp Physiol. 2003;285:183-92.

8. Chau JY, Grunseit AC, Chey T, et al. Daily sitting time and all-cause mortality: a meta-analysis. PLoS One. 2013;8:e80000.

9. Office of Disease Prevention and Health Promotion (2008) Subcommittee report: energy balance. https:/health.gov/paguidelines/meetings/200802/ energy.aspx. Accessed 6 Mar 2017.

10. Levine JA, Vander Weg MW, Hill JO, Klesges RC. Non-exercise activity thermogenesis: the crouching tiger hidden dragon of societal weight gain. Arterioscler Thromb Vasc Biol. 2006;26:729-36.

11. Wansink B. Mindless eating: why we eat more than we think. London: Hay House; 2011. 